"This is the peer reviewed version of the following article: Johar M., and Maruyama S. (2014), DOES CORESIDENCE IMPROVE AN ELDERLY PARENT'S HEALTH?, J. Appl. Econ., 29, 965-983, which has been published in final form at 10.1002/jae.2339. This article may be used for non-commercial purposes in accordance with Wiley Terms and Conditions for Self-Archiving." 


\section{Does Coresidence Improve an Elderly Parent's Health?}

\author{
Meliyanni Johar* \\ Economics Discipline Group \\ University of Technology Sydney \\ Po Box 123. Broadway \\ NSW 2007 Australia \\ Phone: +61 295147742 \\ Fax: +61 295147722
}

\author{
Shiko Maruyama \\ ARC Centre of Excellence in Population \\ Ageing Research (CEPAR) \\ University of New South Wales \\ Sydney, NSW 2052 Australia \\ Phone: +6129385 7685 \\ Email: s.maruyama@unsw.edu.au
}

Email: Meliyanni.johar@uts.edu.au

*Corresponding author 


\title{
Does Coresidence Improve an Elderly Parent's Health?
}

\begin{abstract}
It is generally believed that intergenerational coresidence by elderly parents and adult children provides old-age security for parents. Though such coresidence is still the most common living arrangement in many countries, empirical evidence of its benefits to parental health is scarce. Using Indonesian data and a program evaluation technique that accounts for non-random selection and heterogeneous treatment effect, we find robust evidence of a negative coresidence effect. We also find heterogeneity in the coresidence effect. Socially active elderly parents are less likely to be in coresidence, and when they do live with a child, they experience a better coresidence effect.
\end{abstract}

Keywords: Intergenerational coresidence, informal care, elderly health, treatment effect, factor structure model

JEL codes: I12, J1, C31

Funding: This research is supported by the Australian Research Council Discovery Project Grant DP110100773. 


\section{Introduction}

It is widely assumed that living with adult children improves the health outcomes of elderly parents through the provision of valuable family support. Arguably, coresidence is the most comprehensive form of informal care, offering immediate instrumental, emotional, and financial assistance. For generations, intergenerational coresidence has been relied upon to protect the welfare of elderly parents, particularly in developing and middle-income countries where public support systems for the elderly are underdeveloped.

Despite the prevalence of informal care by adult children and its indisputable role in today's aging societies (e.g., OECD, 2005), solid empirical evidence of the presumed beneficial role of coresidence with a child is scarce. On the contrary, nationally representative data sets from numerous countries (e.g., the US, Japan, China, and Indonesia) and many recent studies both show worse health outcomes for parents in intergenerational coresidence than for parents living independently.

Researchers have discussed various pathways through which intergenerational coresidence may affect parental health negatively. Elderly parents may transfer their resources to adult children (Cameron and Cobb-Clark, 2001; Schroder-Butterfill, 2003; Johar and Maruyama, 2011). Excessive reliance and caregiving burden on children may reduce elderly parents' incentive to invest in their health to extend their life (Maruyama, 2012). Economic development and population aging may have reduced the supply of family support by adult children relative to its demand, which leads to tension and conflict between generations and weakens the bargaining position of elderly parents (Asis et al., 1995; Hermalin, 2000; Giles et al., 2003; Lachs and Pillemer, 2004; Zhang, 2004; Chan, 2005; Newberry, 2010; Teo, 2010). Whether the negative effect of 
intergenerational coresidence dominates has significant policy implications, especially for countries that expect to rely on family informal care in the foreseeable future.

This paper aims to advance the literature by separating the real causal effect from various confounding factors. We use data from the Indonesian Family Life Survey (IFLS). The population of interest is elderly parents, defined as elderly individuals who have at least one living adult child. Verifying whether the undesirable correlation is indeed causal is a challenging empirical task because of the absence of experimental data. We follow the program evaluation literature. In our setup, coresidence by an elderly parent and an adult child is referred to as the 'treatment'. The treatment group consists of elderly parents who live with a child and the control group consists of elderly parents who have a child but do not live with a child. The outcome of interest is parental health status and survival.

There are three classes of confounding factors that prevent us from applying a simple regression framework: (1) reverse causality, (2) non-random selection, and (3) heterogeneity in the treatment effect. Reverse causality concerns the possibility that coresidence occurs in response to the deterioration of parental health. To mitigate the potential bias due to reverse causality, we use the panel structure of the IFLS. We use the most recent two waves of the IFLS, IFLS3 (2000) and IFLS4 (2007), and focus on the health and survival outcomes of elderly parents after seven years, conditional on health and coresidence status in the base period. To address non-random selection and heterogeneity, we employ the factor structure model of Aakvick, Heckman, and Vytlacil (2005). This model provides a flexible yet parsimonious and tractable specification that allows us to correct for non-random selection into coresidence and to accommodate 
heterogeneity in the coresidence effect. These confounding factors, while common, have never been adequately addressed by previous studies on this topic.

Non-random selection, especially selection by unobservable factors, may lead to a significant bias. Even after controlling for observed characteristics, coresiding parents may possess very different characteristics from non-coresiding parents, and these differences may result in different health outcomes. For example, the parents who are more likely to coreside may also be healthier, even after controlling for observed health status, thereby biasing the coresidence effect estimate upward.

Heterogeneity in the treatment effect is another concern receiving increasing attention in the program evaluation literature. In our case, it is reasonable to suspect that the coresidence effect would vary by various family characteristics such as health status, economic status, living environment, and closeness among family members. Suppose families experience heterogeneous effects of equal magnitude in opposite directions. Then the resulting overall effect averages zero, and in a homogeneous treatment effect framework, an econometrician will incorrectly conclude that coresidence has no sizable effect on all parents. Furthermore, by examining the extent and patterns of heterogeneity, we can better understand the mechanism behind the coresidence effect and offer relevant input to policymakers. ${ }^{1}$

For our rich, flexible model, identification is a major concern. We employ two identification strategies. First, we exploit the richness of the IFLS to provide exogenous determinants of coresidence decision (i.e. instruments) utilizing Indonesia's multicultural background. Indonesia comprises over 300 distinct ethnolinguistic groups with their own traditional rules and practices, called adat. Adat influences a wide range

\footnotetext{
${ }^{1}$ See Basu (2011) for a discussion of the importance of heterogeneous treatment effect for policies.
} 
of aspects of an Indonesian's life from birth- to death-related matters, including the coresidence decisions of families. We use a collection of adat to fully exploit exogenous variation across adat and to enhance the efficiency of our empirical estimates.

Second, we extend the binary outcome framework of Aakvick, Heckman, and Vytlacil (2005) by allowing for a five-categorical ordered outcome, combining fourcategorical self-assessed health information with the survival status. The original Aakvick, Heckman, and Vytlacil model simultaneously estimates three binary-outcome equations for selection, outcomes under treatment, and outcomes in non-treatment, in which the correlation among three equations is fully parameterized through an unobservable factor; thus the identification of this model is more challenging than standard bivariate binary models. Our extension to the ordered framework allows us to fully utilize the health status information in data to further aid identification, requiring only a few fairly reasonable extra assumptions. We find that this extension greatly improves the stability of estimation procedure and the robustness of results.

Our results are summarized in three key findings. First, a descriptive data analysis reveals significantly worse health outcomes of elderly parents in coresidence. The seven year mortality rate is 5.3 percentage points higher for coresiding parents, despite no marked difference in baseline health between the coresidence and non-coresidence groups.

Second, when we account for non-random selection by unobserved factors, the estimated average treatment effect is to decrease elderly parents' seven year survival rate by 10.0 percentage points, or 1.38 percentage points per year. This finding suggests that previous studies that do not adequately deal with selection on unobservables 
overestimate the coresidence effect. Although this point estimate comes with a wide confidence interval, numerous sensitivity checks consistently find a negative effect, suggesting that the popular belief of positive coresidence effect is unlikely.

Third, the coresidence effect exhibits considerable heterogeneity. The estimated coresidence effect on the treated is significant and strongly negative. The seven year survival rate of elderly parents in coresidence in the base period would be 18.9 percentage points higher if they had lived independently. Both observed and unobserved factors generate this heterogeneity. Part of the heterogeneity is related to parents' social interactions. Elderly parents who work and are involved in community activities are less likely to be in coresidence, and if they do live with a child, they tend to experience a better coresidence effect. Wealth has a protective effect only if parents live without children. These results suggest that excessive parent-child dependence contributes to the negative coresidence effect.

\section{Literature and Indonesian Context}

\subsection{Existing Evidence of Coresidence Effect}

A negative association between parental survival and coresidence with a child is found in many survey data. Maruyama (2012) reports that the three year mortality rate for Japanese parents over 65 who live with children is 3.6 percentage points higher than that of parents who live without children. In China, Li et al. (2009) report that the two year mortality rate for Chinese parents over 77 who live with a child is 5.3 percentage points higher than the overall sample mortality rate. In Indonesia, based on IFLS3 and IFLS4, we find that the seven year mortality rate of elderly parents over 60 is 5.3 percentage points higher if they live with a child. Higher mortality rates for parents in 
coresidence are not unique to Asian countries. Our calculation using the US Health and Retirement Study 2006-2008 shows that the two year mortality rate for coresiding parents over 65 is 4.6 percentage points higher than that of non-coresiding parents.

The literature has accumulated a number of attempts to verify whether this unconditional mean difference indeed reflects the true causal effect of coresidence. Recent studies exploit the wider availability of panel data to address the reverse causality problem, but their findings are mixed. ${ }^{2}$ On the one hand, a few studies find a positive coresidence effect: from the US, Silverstein and Bengtson (1991) and Liang et al. (2005); from China, Chen and Silverstein (2000), Liu and Zhang (2004), Silverstein et al. (2006), and Chen and Short (2008). On the other hand, many studies find that coresidence has a negative effect on parents. In China, Li et al. (2009) find that elderly parents in coresidence are more likely to have daily limitations and are not less likely to die than parents living alone. In Japan, elderly mothers are found to have more than double the risk of heart disease when they coreside with children (Ikeda et al., 2009). They are also found to have higher mortality rates when they are cared for by daughters than by a spouse (Nishi et al., 2010). In Singapore, Chan et al. (2011) find severer depressive symptoms among elderly parents who live with children than among parents who live with children and a spouse. In Israel, Walter-Ginzburg et al. (2002) find that elderly parents who live with children have higher mortality risk than the lone elderly, especially than those who have extensive social engagements.

To the best of our knowledge, Do and Malhotra (2012) and Maruyama (2012) are the only studies that attempt to correct for selection on unobservables. Using an instrumental variable technique, Do and Malhotra (2012) find that coresidence reduces

\footnotetext{
${ }^{2}$ Most early studies, found in the gerontology, sociology, demography, and public health literatures, suffer from reverse causation because they rely mainly on cross sectional analysis (e.g., Pillemer and Suitor, 1991; Ng et al., 2004).
} 
depressive symptoms among South Korean widowed elderly mothers. They use the number of sons as an instrument for coresidence and argue that it is an appropriate instrument in the Korean setting because it is related to traditional rules of coresidence and should not directly affect parental health. Maruyama (2012) applies the same empirical framework as the present study for Japanese data, and finds a significant, negative treatment effect on the treated.

\subsection{Why Negative Coresidence Effect?}

The old age security hypothesis argues that parents have a child and invest in the child's education and health so that the child will repay the parents in the future by providing monetary and non-monetary transfers to the parent (e.g., Nugent, 1985). This motive is particularly relevant in traditional societies that feature close family ties but lack a reliable public support system. If children live with their elderly parents to provide oldage support, coresidence is predicted to have a positive effect on parental health. Using data in the late 1980s from rural Pakistan, Kochar (2000) finds evidence that elderly parents' labor supply decreases with their coresiding children's income.

The literature discusses several mechanisms that overturn this prediction. First, resource transfers, monetary and non-monetary, may flow from parents to children in coresidence. Elderly parents in good health often remain in employment even when they live with adult children (Keaseberry, 2001; Cameron and Cobb-Clark, 2001 and 2005). Parents with a regular income source such as a pension are particularly prone to having dependants, and they often assume full-parenting responsibilities for adult children and grandchildren (Schroder-Butterfill, 2003). Johar and Maruyama (2011) find that most coresidence formation in Indonesia is motivated by the children's need rather than the parents' need. 
Second, coresidence may worsen parental health because excessive reliance and coresidence burdens on children create disincentives for altruistic parents to invest in their health to extend their life. Maruyama (2012) finds supporting evidence for this hypothesis in Japanese families.

Third, children in coresidence may provide no support. Today's economic development and modernization erode traditional filial piety and the authoritarian relationship between generations. This leads to elderly parents being at greater risk of disrespect and neglect (Lachs and Pillemer, 2004; Newberry, 2010). Using data from numerous countries, the literature has documented increasing evidence of internal disagreements and conflicts in shared households due to the clash of values and declining tolerance by the younger generation (Giles et al., 2003; Zhang, 2004).

Behind these three mechanisms is the weakened bargaining position of parents. When demand for old-age support is large and supply is small, the price of old-age security is higher and thereby the coresidence effect is more likely to be negative.

\subsection{Indonesian Context}

Indonesia has a tradition of close family ties and intergenerational coresidence. This tradition was emphasized and reinforced in the 1960s Suharto era as the family principle (kekeluargaan): the father is the heart of the family and respectful children defer to the decisions of the father (Teo, 2010). Most parents expect to live with their child in the old age. At the same time, public welfare support for the elderly is underdeveloped, and a pension is available almost exclusively for public servants and retirees of large firms. When elderly individuals have no child or do not live with a child, they live alone, with a spouse only, or with others such as siblings. These elderly individuals may get support from relatives, neighbors, charity organizations, new marriage, or patronage from 
previous employers. Nursing homes are generally expensive and often not acceptable among Indonesians. Families regard institutional care for elderly parents as taboo.

The supply of informal care increasingly has difficulty meeting demand. The number of Indonesians aged 60 and over is estimated to increase steadily to 28.8 million by 2020 , or 11 percent of total population, from the current level of 7 percent, ${ }^{3}$ while the national fertility rate has fallen from 6.0 births per woman in 1970s to 3.0 in 1990, then to further to 2.3 in $2011 .^{4}$ This implies that there will be a smaller number of children available for elderly parents to rely on. Furthermore, the literature observes a decline in the younger generation's attitudes towards filial piety in economies which have experienced rapid income growth and westernization (Hermalin, 2000; Chan, 2005; Teo, 2010). Modernization also expanded opportunities for children and increased opportunity costs to their staying with elderly parents.

These trends naturally undermine parents' bargaining power in family decisionmaking. Existing studies show that Indonesian elderly parents provide material and practical support to their children, often without reciprocal support (Cameron and CobbClark, 2001; Schroder-Butterfill, 2003). As a result, Indonesian elderly parents in coresidence may well experience a negative coresidence effect.

\section{Estimation}

We adopt the factor structure model of Aakvik, Heckman, and Vytlacil (2005). This framework provides a flexible yet parsimonious and tractable specification that yields easily interpretable expressions for both non-random selection by unobservables and heterogeneity in the coresidence effect. The original Aakvik, Heckman, and Vytlacil

\footnotetext{
${ }^{3}$ Source: ILO (http://www.ilo.org/jakarta/info/public/pr/WCMS_124484/lang--en/index.htm)

${ }^{4}$ Source: CIA World Factbook (http://www.indexmundi.com/g/g.aspx?c=id\&v=31)
} 
model simultaneously estimates three binary equations for (1) selection, (2) treated outcomes, and (3) untreated outcomes. The identification of such a model is challenging for us, because we only have instruments with limited exogenous variation. We extend their binary outcome model by allowing for a five-categorical ordered outcome, combining health status information with the survival outcome. The treatment is coresidence. The treatment group is elderly parents who live with a child, while the control group is elderly parents who have at least one surviving child and do not live with a child. For each elderly parent $i, D_{i}$ denotes treatment status: it takes 1 if the parent coresides with a child, and 0 otherwise. Let $Y_{0 i}$ and $Y_{1 i}$ be two potential outcomes for parent $i$ after seven years in the untreated $\left(D_{i}=0\right)$ and treated $\left(D_{i}=1\right)$ states, respectively. $Y_{0 i}$ and $Y_{1 i}$ are measured by categorical subjective health which can take five possible values: 4 for very healthy, 3 for healthy, 2 for somewhat unhealthy, 1 for unhealthy, and 0 for death. In this framework, it is assumed that $Y_{0 i}$ and $Y_{1 i}$ are defined for everyone, and that these health outcomes are independent across parents.

As our dependent variables are all discrete, we employ a latent index framework. The coresidence equation is specified as

$$
D_{i}^{*}=Z_{i} \beta_{D}-U_{D i}, \quad D_{i}=1 \text { if } D_{i}^{*} \geq 0 ; D_{i}=0 \text { otherwise }
$$

where $Z_{i}$ is a vector of observed characteristics that influence the family's coresidence decision, $\beta_{D}$ denotes its associated parameters, and $U_{D i}$ is a random error term that captures the unobserved costs of coresidence. ${ }^{5} D_{i}^{*}$ thus measures the net utility of coresidence.

\footnotetext{
${ }^{5}$ Following Aakvik, Heckman, and Vytlacil (2005), the error terms in the three equations are defined as costs instead of benefits, without loss of generality.
} 
The health outcome equations for the untreated $(j=0)$ and treated $(j=1)$ states are specified as follows:

$$
\begin{aligned}
& Y_{j i}^{*}=X_{i} \beta_{j}-U_{j i}, \quad j=0,1
\end{aligned}
$$

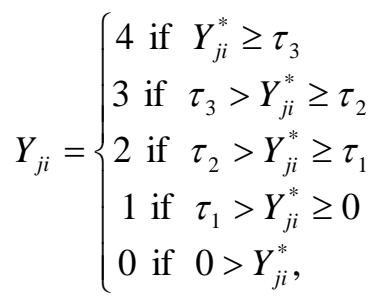

where $X_{i}$ is a vector of observed characteristics, $\beta_{j}$ denotes its associated parameters, $U_{j i}$ is an error term that captures unobserved health shocks, and $\tau_{1}, \tau_{2}$, and $\tau_{3}$ are cutoff parameters. The exclusion restriction is satisfied when $X_{i} \subset Z_{i}$. The latent health variable, $Y_{j i}^{*}$, has a structural interpretation: if it is positive, parent $i$ survives, and a larger value indicates better health. The cut-off points govern which category parent $i$ 's health falls into. Note that our extension of the original Aakvik, Heckman, and Vytlacil model to incorporate health status information requires only a limited number of fairly reasonable extra assumptions: death comes below the worst health status, ${ }^{6}$ and the cutoff parameter values are the same across individuals and across the untreated and treated states. ${ }^{7}$ The model makes no a priori assumption on the cardinality of health status.

Following Aakvik, Heckman, and Vytlacil (2005), we assume that the error terms in equations (1) and (2) are governed by the following normal factor structure:

\footnotetext{
${ }^{6}$ This is a standard assumption in the health economics literature (e.g. Grossman's health capital model and the QALY weights literature). Also, beside mortality, subjective health is the most commonly used measure of individual health in the literature (Banks and Smith, 2011). Subjective health summarizes various aspects of individual health and has been found to be highly correlated with life expectancy and the prevalence of chronic diseases.

${ }^{7} \mathrm{We}$ assume that the four health categories provide a common metric for Indonesian elderly parents, at least approximately. Our approach is not appropriate if each parent perceives the categories and assesses their health in a significantly different way.
} 


$$
U_{D i}=-\theta_{i}+\varepsilon_{D i}, U_{0 i}=-\alpha_{0} \theta_{i}+\varepsilon_{0 i}, \text { and } U_{1 i}=-\alpha_{1} \theta_{i}+\varepsilon_{1 i}
$$

where each of the random terms $\left(\theta, \varepsilon_{D}, \varepsilon_{0}, \varepsilon_{1}\right)$ is assumed to follow the i.i.d. standard normal. ${ }^{8}$ This specification implies that

(4) $\operatorname{Cov}\left(U_{D}, U_{0}\right)=\alpha_{0}, \operatorname{Cov}\left(U_{D}, U_{1}\right)=\alpha_{1}$, and $\operatorname{Cov}\left(U_{0}, U_{1}\right)=\alpha_{0} \alpha_{1}$.

Estimation relies on the maximum likelihood method. The likelihood function has the form

$$
L=\prod_{i=1}^{N} \int \operatorname{Pr}\left(D_{i}, Y_{i} \mid X_{i}, Z_{i}, \theta\right) \phi(\theta) d \theta
$$

where $\phi$ is the standard normal probability density function. Let $\Phi$ denote the standard normal cumulative distribution function. The joint probability is given by:

$$
\operatorname{Pr}\left(D_{i}, Y_{i} \mid X_{i}, Z_{i}, \theta_{i}\right)=\operatorname{Pr}\left(D_{i} \mid Z_{i}, \theta\right) \operatorname{Pr}\left(Y_{i} \mid X_{i}, D_{i}, \theta\right)
$$

where

$$
\operatorname{Pr}\left(D_{i} \mid Z_{i}, \theta\right)=\Phi\left(Z_{i} \beta_{D}+\theta_{i}\right)
$$

and for $j=0,1$,

$$
\begin{aligned}
& \operatorname{Pr}\left(Y_{j i}=4 \mid X_{i}, D_{i}=j, \theta_{i}\right)=\Phi\left(X_{i} \beta_{j}+\alpha_{j} \theta_{i}-\tau_{3}\right), \\
& \operatorname{Pr}\left(Y_{j i}=3 \mid X_{i}, D_{i}=j, \theta_{i}\right)=\Phi\left(X_{i} \beta_{j}+\alpha_{j} \theta_{i}-\tau_{2}\right)-\Phi\left(X_{i} \beta_{j}+\alpha_{j} \theta_{i}-\tau_{3}\right), \\
& \operatorname{Pr}\left(Y_{j i}=2 \mid X_{i}, D_{i}=j, \theta_{i}\right)=\Phi\left(X_{i} \beta_{j}+\alpha_{j} \theta_{i}-\tau_{1}\right)-\Phi\left(X_{i} \beta_{j}+\alpha_{j} \theta_{i}-\tau_{2}\right), \\
& \operatorname{Pr}\left(Y_{j i}=1 \mid X_{i}, D_{i}=j, \theta_{i}\right)=\Phi\left(X_{i} \beta_{j}+\alpha_{j} \theta_{i}\right)-\Phi\left(X_{i} \beta_{j}+\alpha_{j} \theta_{i}-\tau_{1}\right), \text { and } \\
& \operatorname{Pr}\left(Y_{j i}=0 \mid X_{i}, D_{i}=j, \theta_{i}\right)=1-\Phi\left(X_{i} \beta_{j}+\alpha_{j} \theta_{i}\right) .
\end{aligned}
$$

To integrate $\theta_{i}$, a numerical approximation by Gauss-Hermite quadrature is used.

An advantage of using the factor structure model is that the mean treatment parameter and the distributions of the treatment parameter can be obtained from the

\footnotetext{
${ }^{8}$ The normality assumption guarantees the following standard assumptions: (i) $\left(U_{D}, U_{0}\right)$ and $\left(U_{D}, U_{1}\right)$ are independent of $(Z, X)$; (ii) $\left(Y_{0}, Y_{1}\right)$ have finite first moments; and (iii) $1>\operatorname{Pr}(D=1 \mid X)>0$.
} 
estimated structural parameters. Let $\Delta$ denote the treatment effect with regard to survival for a given parent: $\Delta=1\left[Y_{1} \geq 1\right]-1\left[Y_{0} \geq 1\right]$. Four quantities of interests are: (i) the average treatment effect (ATE); (ii) the average treatment effect on the treated (ATT) and on the untreated (ATUT); (iii) the marginal treatment effect (MTE); and (iv) the marginal effect of covariate $x_{k}$ on the ATE. Parameters (i) through (iii) measure the average effect under different conditions. The $A T E$ measures the average effect for a parent chosen at random from the population. The ATT and ATUT measure the average effect for a parent who is in coresidence and for a parent who is not in coresidence, respectively. The MTE measures the average effect for a parent who is indifferent to coresidence for given values of covariates. Specifically, it is the average effect for a parent who is indifferent between coresiding and living independently if the (observed) instrument is externally set so that $Z \beta_{D}=U_{D}=u$ (Equation (1)). A high value of $u$ is associated with a high net cost of coresidence. For small values of $u$, the MTE is the average effect for a parent with unobserved characteristics that make the parent more likely to choose coresidence. The overall expected value of MTE is ATE. The marginal effect of observed characteristics on the ATE, (iv), tells us how the treatment effect varies across covariates and is informative in inferring the mechanism underlying the causal effect. Table 1 summarizes these parameters. We also compute the distributional parameters for the events, $\Delta=1, \Delta=0$, and $\Delta=-1$. The probability of a positive treatment effect, $\operatorname{Pr}(\Delta=1 \mid X=x) \equiv \operatorname{Pr}\left(Y_{1} \geq 1, Y_{0}=0 \mid X=x\right)$ is calculated as follows:

(8) $\operatorname{Pr}\left(Y_{1} \geq 1, Y_{0}=0 \mid X=x\right)=\int \Phi\left(x \beta_{1}+\alpha_{1} \theta\right)\left[1-\Phi\left(x \beta_{0}+\alpha_{0} \theta\right)\right] \phi(\theta) d \theta$.

$\operatorname{Pr}(\Delta=0 \mid X)$ and $\operatorname{Pr}(\Delta=-1 \mid X)$ are calculated in the same manner.

[Insert Table 1] 
Summary estimates of all quantities of interest are found by integration over the empirical distribution of $X$. Standard errors are computed using the delta method.

\section{Data}

The data is derived from the Indonesia Family Life Survey (IFLS), a nationally representative longitudinal study of Indonesian households, collected by the RAND Corporation in collaboration with several Indonesian universities (Thomas et al., 2001). The IFLS began in 1993 with follow-ups administered in 1997, 2000, and 2007. We use the latest two waves of the IFLS: IFLS3 (2000), which provides base year information, and IFLS4 (2007), which provides health outcome information seven years later. The population of interest is elderly parents: individuals aged 60 years or older who have at least one adult child (aged 15 or above) in the base year. ${ }^{9}$ We exclude elderly parents whose spouse is younger than 55 to avoid the complication due to the presence of a non-elderly parent. Both the husband and wife are included as two observations when both of them are aged 60 or older. Our final sample consists of 1,768 elderly parents, of whom 69.8 percent lived with at least one child in 2000.

The dependent variable is a five-category health outcome variable that takes a value of zero for death between 2000 and 2007. If an elderly parent survives, the dependent variable takes a value between 1 and 4, corresponding to the four selfassessed health levels. The distribution of the health outcome variable is shown in Table 2. It is lumpy around the two middle categories. Respondents appear to be conservative about placing themselves at the extremes of the health distribution. The sample seven

\footnotetext{
${ }^{9}$ This age threshold has been used by previous Indonesian studies (Hermalin, 2000; Cameron and CobbClark, 2001; Johar and Maruyama, 2011). The child may be a biological child, a stepchild, or an adopted child. Our definition of elderly parents does not include individuals who have only a child-in-law.
} 
year mortality rate is 31.4 percent (4.0 percent per annum). The high mortality rate reflects the shorter life expectancy in Indonesia.

\section{[Insert Table 2]}

Table 2 also shows negative association between parental health and coresidence. Such association could be observed if parents with worse health conditions were more likely to be in coresidence. In Indonesian families, however, such reverse causation is unlikely. The baseline health status reported in the last two rows of Table 2 shows no substantial difference by coresidence status. Figure 1 clearly illustrates the negative association regardless of baseline health status suggesting that the negative association runs from coresidence to parental health.

\section{[Insert Figure 1]}

Table 3 provides a description of all the variables used in this study. Individual characteristics include age, sex, baseline health conditions, economic status, and the presence and age of a spouse. For baseline health, we use self-assessed health and health conditions. The latter is constructed as the first factor from a factor analysis based on twelve health conditions. ${ }^{10}$ Socio-economic status includes working status, the presence of pension payments, education, ownership of the residential house, and household wealth measured in deciles. ${ }^{11}$

\section{[Insert Table 3]}

The last group of variables in Table 3 are our instruments. We use a combination of community-level and individual-level instruments. The community-level instruments are constructed based on adat (traditional practices) regarding inheritance and living

\footnotetext{
${ }^{10}$ The twelve measures are: time taken to sit and stand five times; two indicators for suffering from chest pain and persistent wounds; and the ability to perform nine activities of daily life (the full survey instruments can be accessed from http://www.rand.org/labor/FLS/IFLS.html).

${ }^{11}$ Wealth includes real estate, vehicles, jewellery, household appliances, livestock, receivables, and savings. Deciles are computed using the full sample of the IFLS households.
} 
arrangements. A community is the smallest administrative unit in Indonesia and consists of 2,500 family heads on average. ${ }^{12}$ The IFLS contains 312 communities. Because communities in Indonesia are multicultural, a community does not uniquely determine adat, so the IFLS records the dominant adat in the community. For our purposes, we use the following adat variables: whether the parent's house is traditionally transferred to the child in coresidence when the parent dies; whether inheritance is traditionally unequally distributed according to a child's gender, birth order, and provision of informal care; how inheritance is traditionally shared among a bereaved family; and whether children live with parents after marriage. ${ }^{13}$ Each adat variable is binary, and we use a collection of them to fully exploit exogenous variation to enhance efficiency.

We argue that adat provides valid instruments. In Indonesian communities, adat is still relevant, with only a fifth of IFLS communities indicate that "only a few people understand and still remember traditional laws" (IFLS2). Adat affects a family's coresidence decision through social pressures and incentives, although parents do not make an explicit agreement in advance with a child to take care of or live with them in their old age. The tradition of bequeathing a house to children, for example, puts extra pressure on parents to pass it on to children, creating incentives for children to live with their parents

While adat influences the coresidence decisions of families, it is hard to imagine that adat directly improves or worsens someone's health, conditional on the baseline health and other covariates. A possible concern over the validity of adat as instruments arises if inheritance rules influence the amount and quality of informal care by altering

\footnotetext{
${ }^{12}$ Four administrative units in Indonesia from smallest to largest are: community or desa (village), kecamatan (district), kabupaten (municipality), and province (e.g. Jakarta). Today, there are 33 provinces, 497 kabupaten, over 6,500 kecamatan, and over 75,000 communities.

${ }^{13}$ Adat information was collected only twice, in IFLS2 and IFLS4. We use IFLS2 as it is closer to IFLS3.
} 
children's incentive. In the Indonesian setting, however, there is little room for children to behave in such a strategic way, because elderly parents typically have very small non-property wealth to bequeath and houses are the major asset to be inherited. As a house is an indivisible asset, the amount and quality of care a coresiding child provides cannot substantially affect the level of inheritance the child expects.

To reinforce the adat instruments, we also use two individual-level instruments: (1) whether the respondent's spouse was chosen by his/her parents, and (2) the number of the children the respondent has. The former influences the coresidence decision because if it is a family's tradition to choose a son-in-law or daughter-in-law, the choice ought to reflect the parents' preferences for coresidence. The latter instrument affects the coresidence decision because having more children increases the likelihood of coresidence with a child. At the same time, these two instruments are unlikely to directly affect a parent's health transition, conditional on the baseline health. ${ }^{14}$

Table 4 provides descriptive statistics of all the covariates and instruments. Parents in coresidence tend to be younger and do not live with a spouse, or live with a younger spouse if married. They have younger children, greater wealth, and more children. They tend to live in a non-rented house and in communities that traditionally reward children equally and in communities where parents have greater power in the marital decision of their children.

\section{[Insert Table 4]}

\section{Results}

\footnotetext{
${ }^{14}$ The latter instrument violates the exogeneity condition if the presence of siblings affects how a child cares for his/her parents, as discussed in Bernheim et al.'s (1985) strategic bequest motive hypothesis. In the Indonesian setting, however, the strategic bequest motive appears to be limited, because of very little non-property wealth to bequeath.
} 
In this section, we first present simple linear survival models to outline characteristics of the data and to discuss the validity of the instruments. We then report the results of the full model. At the end of the section, we discuss the robustness of our results.

\subsection{Linear Survival Analysis}

The dependent variable is seven year survival. Table 5 reports three simple estimates of the coresidence effect: [1] the unconditional average effect; [2] the average effect from a linear probability model (LPM); and [3] the average effect from a linear probability model with instruments (LPM-IV).

\section{[Insert Table 5]}

The unconditional average effect is significant at the 5 percent level, showing that the seven year mortality rate for parents in coresidence is 5.3 percentage points higher than for those who have a child but live independently. Column [2] indicates a mild negative selection on observables: once we control for observable characteristics, the average coresidence effect reduces to 3.6 percentage points and becomes insignificant, but more than half of the mortality gap remains. When we also control for selection on unobservables (column [3]), the coresidence effect increases to 8.5 percentage points. Although not significant, this increase in the size of coresidence effect indicates the presence of a positive selection bias due to unobservables. Elderly parents with unobservable traits that contribute to their survival probability — such as inherent health, mental strength, and strong family altruism and reciprocity — are more likely to enter coresidence, after controlling for observables.

Standard tests support the validity of our instruments. In the first-stage regression, the instruments are jointly significant $(\mathrm{p}$-value $=0.00)$, indicating that they are strong predictors of coresidence. The overidentification test of the independence of all 
instruments and the error term in the survival equation cannot be rejected (pvalue $=0.353)$.

\subsection{Coresidence Equation}

The full model estimates the coresidence equation and the two health outcome equations simultaneously. Table 6 reports the coefficient estimates of the coresidence equation (Equation (1)), which should be interpreted as correlation rather than causation, because unobserved confounding factors may exist.

\section{[Insert Table 6]}

The statistical significance of many covariates confirms non-random selection into coresidence. Coresidence is less likely for old couples and mothers. This is consistent with existing Indonesian studies (Schroder-Butterfill, 2003; Johar and Maruyama, 2011) and other studies from neighbouring Southeast Asian countries (Chan, 2005). Holding parental age constant, the parents of younger children are more likely to coreside. Coresidence is also more likely when parents work, receive a pension, have smaller wealth, own a house, engage in the community, and live in an urban area as a non-Muslim. The two health variables have no significant power in explaining coresidence; hence, it is not the baseline health gap that generates the negative coresidence effect. Most adat rules are significant predictors of coresidence.

\subsection{Health Outcome Equations}

Table 7 reports the results of the two health outcome equations. In both states, younger parents are more likely to have a better health outcome, and so are mothers, reflecting the higher life expectancy of females. Naturally, subjective health and existing health conditions at the baseline are strong predictors of health outcomes seven years later. Work, a spouse, and community involvement lead to a better health outcome if parents 
live with a child. Our interpretation of these findings is the importance of parents' social interactions to avoid excessive reliance on coresiding children and associated undesirable effects of coresidence. Wealth is another variable with a significantly contrasting effect across the coresidence states: greater wealth improves the health of parents only when the parent does not live with a child. While wealth potentially protects health, it may attract more dependent children (Johar and Maruyama, 2011). The number of siblings has a significant protective effect only when a parent lives without a child, suggesting the role that siblings may play as alternative care providers in the absence of children.

\section{[Insert Table 7]}

The three cut-off points for ordered health outcomes are relative to the threshold for death that is normalized to zero. They are precisely estimated and have reasonable values. The large difference between $\hat{\tau}_{2}$ and $\hat{\tau}_{3}$ reflects the fact that a very small share of parents answered that they were "very healthy".

The factor structure parameter, $\theta$, enters the health outcome equations with the coefficient parameters, $\alpha_{0}$ and $\alpha_{1}$. A model with no selection on unobservables implies $\alpha_{0}=\alpha_{1}=0$. The estimates of $\alpha_{0}$ and $\alpha_{1}$ are reported in the row with the heading Factor $(\theta)$. They have different signs, capturing heterogeneity in the treatment effect due to unobservables, although a model without selection cannot be formally rejected $(\mathrm{p}$-value $=0.23)$

\subsection{Treatment Effects}

Based on the full model, the treatment effect parameters are computed and reported in Table 8 . The ATE predicts a higher mortality rate by 10 percentage points or 1.4 percentage points per annum on a parent drawn randomly from the entire elderly 
parent population. Although not significant at the conventional significance levels, this estimate indicates that a substantially positive average coresidence effect is unlikely to exist. The next rows present the distributional parameters of the ATE: if coresidence were randomly assigned, 12.5 percent of parents would avoid death due to coresidence, 65.0 percent would not be affected by coresidence, and 22.5 percent would die because of coresidence.

\section{[Insert Table 8]}

The ATT is significant at the 5 percent level, implying that if parents in coresidence had not chosen to coreside, their seven year survival rate would have been 18.9 percentage points higher (or 2.5 percentage points per annum). The ATUT is estimated to be positive 0.123 . These estimates indicate heterogeneity in the coresidence effect: elderly parents who were in coresidence in the base year are those who are prone to suffer from an undesirable treatment effect.

Heterogeneity in the coresidence effect can be attributed to observed and unobserved factors. Table 9 reports correlation estimates between observables, unobservables, and the treatment effect. The first three rows provide correlations among the selection and health outcome variables in terms of observed and unobserved factors. The two health outcome equations $\left(Y_{0}^{*}, Y_{1}^{*}\right)$ are strongly and positively correlated due to the strong positive correlation of observable factors $\left(X \beta_{0}, X \beta_{1}\right)$. The unobserved factors $\left(U_{0}, U_{1}\right)$ are negatively correlated. The correlation between selection and health outcome exhibits different signs across the coresidence and non-coresidence states. In terms of both observables and unobservables, factors that induce coresidence are positively correlated with factors that benefits health outcomes in the non-coresidence state, whereas the factors that induce coresidence are negatively correlated with health factors 
in the coresidence state. Taking these relationships altogether, the last three rows show the negative relationship between coresidence and the coresidence effect, where both observables and unobservables contribute to the negative relationship.

\section{[Insert Table 9]}

Figure 2 plots the point estimate of the $M T E$ with its 95 percent confidence intervals. The horizontal axis represents the value of $U_{D}$, which is labelled by its cumulative probability value. A higher value of $U_{D}$ implies a lower probability of coresidence (see Equation (1)). The upward sloping MTE curve implies that in terms of unobservables, parents who are more likely to be in coresidence (i.e. those who have a small $U_{D}$ ) are more likely to experience a significant health decline under coresidence than those who are less likely to coreside. This reflects the negative $\operatorname{Corr}\left(U_{D}, U_{1}-U_{0}\right)$. Recall that in our notation, a larger value of $\left(U_{1}-U_{0}\right)$ makes the coresidence effect worse. Unobserved factors underlying the heterogeneous effect might capture the dependence of children, parental altruism, other intergenerational relationship, or unobserved physical or mental health disposition. In the present analysis, we are agnostic about the underlying unobservables.

\section{[Insert Figure 2]}

Observables also generate heterogeneity in the coresidence effect, and they are informative in inferring the mechanism underlying the causal effect. Table 10 reports the marginal effects of observed characteristics on the ATE. Significant marginal effect is found for only one variable - community engagement. Parents who have little community engagement tend to be those who experience greater health deterioration due to coresidence. The same relationship is found for working and marital status, although with much lower significance. These findings indicate the importance of social 
interaction to avoid an undesirable coresidence effect on parental health. Social activities may help parents to avoid excessive dependence on coresiding children and associated conflicts, by maintaining their mental well-being and subjective happiness. The positive effect of social interactions may also come from changes in children's behavior. In small closed communities, more widely networked parents may generate incentives to children to do well in their education and job, and to increase the attention and care given to parents to maintain a good family image and avoid being labelled as an ungrateful child. ${ }^{15}$

[Insert Table 10]

The use of ordered health outcomes allows us to compute the ATE on health status. Table 11 shows the conditional ATEs, with associated unconditional transition rates for reference. For parents who are healthy in the base year, coresidence lowers their probability of becoming 'very healthy' by 5.17 percentage points and 'somewhat healthy' by 8.92 percentage points. At the same time, their probability of health deterioration into the two unhealthy states increases by 4.3 percentage points and their probability of death increases by 9.14 percentage points. The baseline health status does not affect the coresidence effect: coresidence similarly shifts the health outcome distribution of those who are unhealthy in the base year downward.

\section{[Insert Table 11]}

\subsection{Robustness of Results}

The estimated ATE and ATT are 10.0 and 18.9 percentage points, respectively (1.4 and 2.5 percentage points per annum). These large effects are not implausible given that we are concerned with the population aged 60 and above in Indonesia. The national life

\footnotetext{
${ }^{15}$ A reverse causation might be possible: parents limit their social interaction when taking care of their children occupies their time and resources. Disentangling the causal mechanism here is beyond the scope of this research.
} 
expectancy at age 60 at the study period is around 77.4 years. ${ }^{16}$ The seven year mortality rate for our sample is 31.4 percent, and the seven year mortality rate for those above 80 is 60.1 percent. The unconditional mean difference by coresidence status obtained from the raw data is already as large as 5.3 percentage points (Table 5), and 11.0 percentage points if we only use those above 70 .

However, because we estimate a flexible model by relying on community-level instruments, the robustness of our results may be of concern. To ensure the robustness of our results we provide a series of sensitivity analyses. First, we estimate our main model with various sets of instrumental variables. We experiment with different permutations of the instruments, including those used in our preferred model, two additional adat variables, several family-level variables, and community-level time trends in the age structure and family size between 1993 and 2000. The negative coresidence effect is found in all specifications, indicating our results are not driven by a particular instrument or by a particular combination of instruments. ${ }^{17}$ Furthermore, we also estimate a variant of our preferred model in which Inherit_care is included as one of the covariates rather than as an instrument. This is to address to the concern that the inheritance rule that relates to the amount of care might influence the amount and quality of care a child in coresidence provides. If this specific adat influences care quality, it violates the exogeneity condition. The results confirm that this is not the case: the estimated $A T E$ and $A T T$ are almost the same as our preferred model $(-10.1$ and 18.6, respectively), and the ATE does not vary by Inherit_care.

As another instrumental variable validation test, we study how our covariates vary along our instruments. If the covariates in the health outcome equation and the

\footnotetext{
${ }^{16}$ Source: Medika Consulting, "Indonesia life expectancy history", Indonesia (http://www.medikaconsulting.com/website/26378/images/htmleditorfiles/INDONESIA-health-data-medikaconsulting.pdf).

${ }^{17}$ Results are in online Appendix to the paper.
} 
instruments always move together, this raises concerns about the instruments. Since we have multiple instruments, we run a simple probit regression of coresidence on only the instruments, generate a propensity score, and divide it into quartiles. At the 5\% significance level, we find that the propensity scores are: (1) balanced (statistically indifferent) across top and bottom quartiles for 10 of the 18 covariates; (2) balanced across the top and bottom half of the distribution for 2 covariates; (3) non-monotonic for 4 covariates; and (4) different in the top quartile to any other quartiles for 2 covariates but the difference is not significant at the $1 \%$ level. Thus, it is fairly reasonable to conclude that our instruments pass this test.

To confirm robustness with respect to econometric specification, we estimate the ATE based on several competing models. The results reported in Table 12 are summarized as follows. While addressing selection on unobservables increases the size of the ATE, the use of our instruments leads to large standard errors. Allowing heterogeneous treatment effect also increases the standard errors because identification becomes more challenging. On the other hand, combining mortality and health information increases precision. When we attempt binary outcome models that addresses selection on unobservables and heterogeneous treatment effect, their estimates are sensitive to specifications and convergence is often unstable. The results of threecategory models, in which we aggregate "very healthy" and "somewhat healthy" into "healthy" and "somewhat unhealthy" and "unhealthy" into "unhealthy", indicate the robustness of our results with respect to the way we construct our dependent variable. Overall, the direction of the ATE is consistently negative.

[Insert Table 12 here] 
We also conduct a simple goodness-of-fit test. Based on 5,000 Monte Carlo simulation draws of $\left(\theta, \varepsilon_{D}, \varepsilon_{0}, \varepsilon_{1}\right)$, we check to what extent our models can correctly predict both the coresidence status and five-categorical health outcome. Our baseline specification is an independent combination of a binary probit for coresidence and a standard ordered probit for health outcomes. This baseline model correctly predicts $24.7 \%$ of the observed data, whereas our factor structure model correctly predicts $25.0 \%$. Thus our factor structure model is able to reproduce the observed data fairly reasonably.

As another sensitivity analysis, we re-estimate the model using three alternative health measures: (1) the number of days in the last four weeks in which the respondent stayed in bed due to illness; (2) the number of days in the last four weeks in which the respondent missed primary activities due to poor health; and (3) the interviewer's health assessment. ${ }^{18}$ These health measures are combined with mortality. All three health measures produce consistent findings: a negative $A T E$ of similar magnitude and a much worse $A T T$, illustrating the robustness of our findings.

Lastly, although the negative sign of the coresidence effect is consistently found throughout the above robustness checks, the large standard error of the ATE and the large magnitude of the ATT may cast doubt over the precision and generalizability of our results. Our conservative view is that, even though we lack a strong evidence of a negative $A T E$, given the magnitude and robustness of the ATE, a sizeable positive coresidence effect on parental health is unlikely. The fact that our instruments mainly consist of community-level dummy variables is likely to be one reason of the large standard errors. Future research with better data is required to further validate our results. The distributional assumptions of the single factor structure may be a source of

\footnotetext{
${ }^{18}$ Guided by the empirical distribution of each variable, we construct ordered variables: the number of days in bed is a binary variable ( 0 day, $1+$ day); the number of missed days has four categories ( 0 day, $0-1$ days, 4-7 days, 7+ days); and the nurse assessment also has four groups (1-4, 5, 6, 7-9).
} 
the large ATT, because its functional form assumption restricts the way the heterogeneous treatment effect is distributed (Figure 2). The implication of the onefactor structure assumption in our context is left for future research.

\section{Conclusion}

In many countries where the public old age welfare program is underdeveloped or nonexistent, coresidence with a child has been the most comprehensive form of old age security for elderly parents and is expected to remain prevalent in the foreseeable future. ${ }^{19}$ In this paper, we investigate whether coresidence has a positive effect on parental health. We achieve this by addressing non-random selection on unobservables and heterogeneity in the coresidence effect - two major problems in the evaluation literature that have been largely overlooked in previous studies on this topic. We find evidence of negative coresidence effect and heterogeneity in the coresidence effect. Elderly parents who are more likely to experience a negative effect tend to self-select into coresidence. Our results also suggest that those who lack social interactions are more likely to live with children and suffer from a negative coresidence effect.

Our findings have important policy implications for relying on informal care as the primary strategy to provide old age security. The population is aging rapidly in middle-income and developing countries in Asia. At the same time, modernization erodes the customs and values of large traditional families in these countries. In response to these trends, politicians often emphasize the value of 'traditional families' in public rhetoric (Teo, 2010). Some countries even offer financial incentives for filial

\footnotetext{
${ }^{19}$ Throughout Asia, it is estimated that the Asian population aged over 60 will increase almost three times from 9 percent in 2000 to 24 percent by 2050 .
} 
piety; for example, Malaysia and Singapore give subsidies to coresiding families. ${ }^{20}$ The negative coresidence effect, however, suggests that this traditional living arrangement and the policies which encourage it may result in an unintended adverse outcome in the health of the elderly. In developing aged care infrastructures, policymakers should recognize the importance of the elderly's social participation in local communities. There may be scope for designing community-based programs for elderly individuals to expand their social activities network outside their family.

\footnotetext{
${ }^{20}$ Malaysia provides tax incentives for in-home care of sick older persons and Singapore has housing tax incentives for children who live with their elderly parents.
} 


\section{References}

Aakvik A, Heckman JJ, Vytlacil RJ. 2005. Estimating treatment effects for discrete outcomes when responses to treatment vary: An application to Norwegian vocational rehabilitation programs. Journal of Econometrics 125: 15-51.

Asis M, Domingo L, Knodel J, Mehta K. 1995. Living arrangements in four Asian countries: A comparative perspective. Journal of Cross-Cultural Gerontology 10: $145-162$.

Banks J, Smith JP. 2011. International comparisons in health economics: Evidence from aging studies. RAND Working Paper WR-880.

Basu A. 2011. Economics of individualization in comparative effectiveness research and a basis for a patient-centered health care. Journal of Health Economics 30(3): 549-559.

Bernheim, D, Shleifer, A, Summers, L. 1985. The strategic bequest motive. Journal of Political Economy, 93(6): 1045-1076.

Cameron L, Cobb-Clark D. 2001. Old-age support in developing countries: Labour supply, intergenerational transfers and living arrangements. IZA Working Paper 289.

Cameron L, Cobb-Clark D. 2005. Do coresidency with and financial transfer from children reduce the need for elderly parents to work in developing countries? Centre for Economic Policy Research Discussion paper no 508. Australian National University.

Chan A. 2005. Aging in Southeast and East Asia: issues and policy directions. Journal of Cross Cultural Gerontology 20: 269-284. 
Chan A, Malhotra C, Malhotra R, Østbye T. 2011. Living arrangements, social networks and depressive symptoms among older men and women in Singapore. International Journal of Geriatric Psychiatry 26(6): 630-639.

Chen F, Short SE. 2008. Household context and subjective well-being among the oldest old in China. Journal of Family Issues 29(10): 1379-1403.

Chen X, Silverstein M. 2000. Intergenerational social support and the psychological well-being of older parents in China. Research on Aging 22(1): 43-65.

Do Y, Malhotra C. 2012. The effect of coresidence with an adult child on depressive symptoms among older widowed women in South Korea: An instrumental variables estimation. Journal of Gerontology B: Psychological Sciences and Social Sciences 67B (3): 384-391.

Giles H, Noels KA, Williams A et al. 2003. Intergenerational communication across cultures: Young people's perceptions of conversations with family elders, nonfamily elders and same-age peers. Journal of Cross-Cultural Gerontology 1(3): 132.

Hermalin A. 2000. Ageing in Asia: Facing the crossroads. Comparative Study of the Elderly in Asia Research Reports 00-55, Population Studies Center, University of Michigan.

Ikeda A, Iso H, Kawachi I, Yamagishi K, Inoue M, Tsugane S. 2009. Living arrangement and coronary heart disease: The JPHC study. Heart 95: 577-583.

Johar M, Maruyama S. 2011. Intergenerational cohabitation in modern Indonesia: Filial support and dependence. Health Economics 20(S1): 87-94.

Keasberry IN. 2001. Elder care and intergenerational relationships in rural Yogyakarta, Indonesia. Ageing and Society 21(5): 641-665. 
Kochar A. Parental benefits from intergenerational coresidence: Empirical evidence from rural Pakistan. Journal of Political Economy 108(6): 1184-1209.

Lachs MS, Pillemer K. 2004. Elder abuse. Lancet 364(9441): 1263-1272.

Li LW, Zhang J, Liang J. 2009. Health among the oldest-old in China: Which living arrangements make a difference? Social Science \& Medicine 68: 220-227.

Liang J, Brown JW, Krause NM, Ofstedal MB, Bennett J. 2005. Health and living arrangements among older Americans: Does marriage matter? Journal of Aging and Health 17(3): 305-335.

Liu G, Zhang Z. 2004. Sociodemographic differentials of the self-rated health of the oldest-old Chinese. Population Research and Policy Review 23(2): 117-133.

Maruyama S. 2012. Inter vivos health transfers: Final days of Japanese elderly parents. UNSW Australian School of Business Research Paper, No. 2010 ECON 05.

Newberry J. 2010. The global child and non-governmental governance of the family in post-Suharto Indonesia. Economy and Society 39(3): 403-426.

Ng KM, Lee TM, Chi I. 2004. Relationship between living arrangements and the psychological well-being of older people in Hong Kong. Australasian Journal on Ageing 23: 167-171.

Nishi A, Tamiya N, Kashiwagi M, Takahashi H, Sato M, Kawachi I. 2010. Mothers and daughters-in-law: A prospective study of informal care-giving arrangements and survival in Japan. BMC Geriatrics 10:61.

Nugent JB. 1985. The old-age security motive for fertility. Population and Development Review 11(1): 75-97.

OECD. 2005. Long-term care for older people. Paris. OECD. 
Pillemer K, Suitor JJ. 1991. "Will I ever escape my child's problems?” Effects of adult children's problems on elderly parents. Journal of Marriage and Family 53(3): $585-594$.

Schroder-Butterfill E. 2003. Pillars of the family support provided by the elderly in Indonesia. Oxford Institute of Ageing Working Papers, No.303.

Silverstein M, Bengtson VL. 1991. Do close parent-child relations reduce the mortality risk of older parents? Journal of Health and Social Behavior 32(4): 382-395.

Silverstein M, Cong Z, Li S. 2006. Intergenerational transfers and living arrangements of older people in rural China: Consequences for psychological well-being. Journal of Gerontology: Social Sciences 61B: S256-S266.

Teo Y. 2010. Asian families as sites of state politics: Introduction. Economy and Society 39(3): 309-316.

Thomas D, Frankenberg E, Smith JP. 2001. Lost but not forgotten: Attrition and followup in the Indonesia family life survey. Journal of Human Resources 36(3): 556592.

Walter-Ginzburg A, Blumstein T, Chetrit A, Modan B. 2002. Social factors and mortality in the old-old in Israel: The CALAS study. Journal of Gerontology: Social Sciences 57B(5): S308-S318.

Zhang YB. 2004. Initiating factors of Chinese intergenerational conflict: Young adults' written accounts. Journal of Cross-Cultural Gerontology 19(4): 299-319. 
Table 1: Quantities of interest

\begin{tabular}{|c|c|c|}
\hline Quantity & Definition & Estimation \\
\hline $\begin{array}{l}\text { ATE } \\
\text { (average } \\
\text { treatment } \\
\text { effect) }\end{array}$ & $\Delta^{A T E}(x) \equiv E(\Delta \mid X=x)$ & $\begin{array}{l}E_{x}\left[\Delta^{A T E}(x)\right]=E_{x}\left[\operatorname{Pr}\left(Y_{1} \geq 1 \mid X=x\right)-\operatorname{Pr}\left(Y_{0} \geq 1 \mid X=x\right)\right] \\
=\int_{X} \int_{\theta}\left[\Phi\left(x \beta_{1}+\alpha_{1} \theta\right)-\Phi\left(x \beta_{0}+\alpha_{0} \theta\right)\right] \phi(\theta) d \theta d F_{X}(x)\end{array}$ \\
\hline $\begin{array}{l}\text { ATT (average } \\
\text { treatment } \\
\text { effect on the } \\
\text { treated) }\end{array}$ & $\Delta^{A T T}(x, z, D=1) \equiv E(\Delta \mid X=x, Z=z, D=1)$ & $\begin{array}{l}E_{x}\left[\Delta^{A T T}(x, z, D=1)\right]=E_{x}\left[\operatorname{Pr}\left(Y_{1} \geq 1 \mid X=x, Z=z, D=1\right)-\operatorname{Pr}\left(Y_{0} \geq 1 \mid X=x, Z=z, D=1\right)\right] \\
=\int_{X} \int_{\theta} \frac{1}{\Phi\left(z \beta_{D} / \sqrt{2}\right)}\left[\Phi\left(x \beta_{1}+\alpha_{1} \theta\right)-\Phi\left(x \beta_{0}+\alpha_{0} \theta\right)\right] \Phi\left(z \beta_{D}+\theta\right) \phi(\theta) d \theta d F_{X}(x)\end{array}$ \\
\hline $\begin{array}{l}\text { ATUT } \\
\text { (average } \\
\text { treatment } \\
\text { effect on the } \\
\text { untreated) }\end{array}$ & $\Delta^{A T U T}(x, z, D=0) \equiv E(\Delta \mid X=x, Z=z, D=0)$ & $\begin{array}{l}E_{x}\left[\Delta^{A T U T}(x, z, D=0)\right]=E_{x}\left[\operatorname{Pr}\left(Y_{1} \geq 1 \mid X=x, Z=z, D=0\right)-\operatorname{Pr}\left(Y_{0} \geq 1 \mid X=x, Z=z, D=0\right)\right] \\
=\int_{X} \int_{\theta} \frac{1}{1-\Phi\left(z \beta_{D} / \sqrt{2}\right)}\left[\Phi\left(x \beta_{1}+\alpha_{1} \theta\right)-\Phi\left(x \beta_{0}+\alpha_{0} \theta\right)\right]\left(1-\Phi\left(z \beta_{D}+\theta\right)\right) \phi(\theta) d \theta d F_{X}(x)\end{array}$ \\
\hline $\begin{array}{l}\text { MTE } \\
\text { (marginal } \\
\text { treatment } \\
\text { effect) }\end{array}$ & $\Delta^{M T E}(x, u) \equiv E\left(\Delta \mid X=x, U_{D}=u\right)$ & $\begin{array}{l}E_{x}\left[\Delta^{M T E}(x, z, D=1)\right]=E_{x}\left[\operatorname{Pr}\left(Y_{1} \geq 1 \mid X=x, U_{D}=u\right)-\operatorname{Pr}\left(Y_{0} \geq 1 \mid X=x, U_{D}=u\right)\right] \\
=\int_{X} \int_{\theta} \frac{1}{\Phi(u / \sqrt{2})}\left[\Phi\left(x \beta_{1}+\alpha_{1} \theta\right)-\Phi\left(x \beta_{0}+\alpha_{0} \theta\right)\right] \Phi(u+\theta) \phi(\theta) d \theta d F_{X}(x)\end{array}$ \\
\hline $\begin{array}{l}\text { Marginal } \\
\text { Effect on } \\
A T E\end{array}$ & $\frac{\partial \Delta^{A T E}(x)}{\partial x_{k}}$ & $\begin{array}{l}E_{x}\left[\frac{\partial \Delta^{A T E}(x)}{\partial x_{k}}\right]=\int_{X} \int_{\theta}\left[\phi\left(x \beta_{1}+\alpha_{1} \theta\right) \beta_{1 k}-\phi\left(x \beta_{0}+\alpha_{0} \theta\right) \beta_{0 k}\right] \phi(\theta) d \theta d F_{X}(x) \\
\text { where } F_{X}(X) \text { is the distribution of } X\end{array}$ \\
\hline
\end{tabular}

Note: $\Delta$ denotes the treatment effect with regard to survival for a given parent: $\Delta=1\left[Y_{1} \geq 1\right]-1\left[Y_{0} \geq 1\right]$. 
Table 2: Distribution of health outcomes after 7 years and baseline health

\begin{tabular}{lllllll}
\hline & All & & \multicolumn{2}{c}{ Non-Coresidence } & \multicolumn{2}{c}{ Coresidence } \\
\cline { 2 - 7 } & Count & $\%$ & Count & $\%$ & Count & $\%$ \\
\hline Total & 1,768 & $100 \%$ & 534 & $100 \%$ & 1,234 & $100 \%$ \\
\hline Health outcomes in 2007 & & & & & & \\
4: Very healthy & 41 & $2.32 \%$ & 15 & $2.81 \%$ & 26 & $2.11 \%$ \\
3: Healthy & 735 & $41.57 \%$ & 247 & $46.25 \%$ & 488 & $39.55 \%$ \\
2: Unhealthy & 385 & $21.78 \%$ & 111 & $20.79 \%$ & 274 & $22.20 \%$ \\
1: Very unhealthy & 52 & $2.94 \%$ & 13 & $2.43 \%$ & 39 & $3.16 \%$ \\
0: Death & 555 & $31.39 \%$ & 148 & $27.72 \%$ & 407 & $32.98 \%$ \\
\hline Baseline health in 2000 & & & & & & \\
Healthy/very healthy & 1,292 & $73.08 \%$ & 396 & $74.16 \%$ & 896 & $72.61 \%$ \\
Unhealthy/very unhealthy & 476 & $26.92 \%$ & 138 & $25.84 \%$ & 338 & $27.39 \%$ \\
\hline
\end{tabular}


Table 3. Definitions of the dependent and explanatory variables

\begin{tabular}{|c|c|}
\hline \multicolumn{2}{|c|}{ Dependent variables } \\
\hline$Y$ & $=0$ for death; 1 for unhealthy; 2 for some unhealthy; 3 for some healthy; 4 for very healthy \\
\hline Survive & $=1$ if elderly parent is alive in $2007 ; 0$ otherwise \\
\hline Coresidence & $=1$ if elderly parent lives with at least one child; 0 otherwise \\
\hline \multicolumn{2}{|c|}{ Explanatory variables } \\
\hline Age & Age \\
\hline Female & $=1$ if female; 0 otherwise \\
\hline Wspouse & $=1$ if live with spouse; 0 otherwise \\
\hline Spouseage & Spouse's age \\
\hline Childage & Age of youngest child \\
\hline Nmsib & The number of siblings \\
\hline Subjhealth & $=1$ for healthy; 0 otherwise \\
\hline Healthconditions & $\begin{array}{l}\text { The first factor from a factor analysis based on } 12 \text { health condition measures: } 9 \text { ADL } \\
\text { indicating difficulty in performing daily task, nurse measurement of time taken to sit and } \\
\text { stand } 5 \text { times, suffering from chest pain and suffering from persistent wound }\end{array}$ \\
\hline Work & $=1$ if currently working for income; 0 otherwise \\
\hline Education & $=0$ for no schooling; 1 for primary school; 2 for higher than primary school \\
\hline Pension & $=1$ if has pension income; 0 otherwise \\
\hline Wealth & Decile of household wealth \\
\hline House & $=1$ if the house is not a rental property (i.e. owned by household member(s)); 0 otherwise \\
\hline Javanese & $=1$ if ethnicity is Javanese (the majority); 0 otherwise \\
\hline Community & \# of participation in a series of community activities in the last 12 months \\
\hline Muslim & $=1$ if Muslim; 0 otherwise \\
\hline Rural & $=1$ if rural area; 0 otherwise \\
\hline Java & $=1$ if reside in provinces in Java Island (most populated) $; 0$ otherwise \\
\hline \multicolumn{2}{|c|}{ Instrumental variables } \\
\hline Inherit_house ${ }^{\wedge}$ & $\begin{array}{l}=1 \text { if traditionally parental house is inherited to the child who lives with the parent when } \\
\text { he/she dies; } 0 \text { otherwise }\end{array}$ \\
\hline Inherit_care ${ }^{\wedge}$ & $\begin{array}{l}=1 \text { if traditionally inheritance sharing rule is based on the amount of care provided to } \\
\text { parents; } 0 \text { otherwise }\end{array}$ \\
\hline Inherit_gender $\wedge$ & $=1$ if traditionally inheritance sharing rule differs for sons and daughters; 0 otherwise \\
\hline Inherit_order ${ }^{\wedge}$ & $=1$ if traditionally inheritance sharing rule is based on child's birth order; 0 otherwise \\
\hline Inherit_child $1^{\wedge}$ & $=1$ if traditionally children are the sole recipient of their mother's inheritance; 0 otherwise \\
\hline Inherit_child $2^{\wedge}$ & $=1$ if traditionally children are the sole recipient of their father's inheritance; 0 otherwise \\
\hline Inherit_child $3^{\wedge}$ & $=1$ if traditionally children share inheritance claim with the grieving parent; 0 otherwise \\
\hline Parenthouse $^{\wedge}$ & $=1$ if traditionally married couples stay at parent's house; 0 otherwise \\
\hline Parentchoose $e^{\wedge}$ & $=1$ if parent chose the respondent's first husband/wife ; 0 otherwise \\
\hline Nmchildren & The number of surviving children \\
\hline Nmchildrensq & Nmchildren squared \\
\hline
\end{tabular}

Note: ^Based on adat survey. 
Table 4. Means and standard deviation of variables

\begin{tabular}{|c|c|c|c|c|c|c|}
\hline & \multicolumn{2}{|c|}{1768 elderly parents } & \multicolumn{2}{|c|}{$\begin{array}{l}1234 \text { parents in } \\
\text { coresidence }\end{array}$} & \multicolumn{2}{|c|}{$\begin{array}{l}534 \text { parents living } \\
\text { without child }\end{array}$} \\
\hline & Means & std.dev & Means & std.dev & Means & std.dev \\
\hline Survive & 0.69 & 0.46 & 0.67 & 0.47 & 0.72 & 0.45 \\
\hline Coresidence & 0.70 & 0.46 & & & & \\
\hline Age & 68.72 & 7.03 & 68.46 & 6.86 & 69.32 & 7.37 \\
\hline Female & 0.58 & 0.49 & 0.59 & 0.49 & 0.57 & 0.49 \\
\hline Wspouse & 0.59 & 0.49 & 0.54 & 0.50 & 0.70 & 0.46 \\
\hline Spouseage* & 66.14 & 7.68 & 65.14 & 7.20 & 67.92 & 8.17 \\
\hline Childage & 30.29 & 9.22 & 29.39 & 9.29 & 32.39 & 8.70 \\
\hline Nmsib & 2.18 & 1.99 & 2.18 & 2.02 & 2.16 & 1.90 \\
\hline Subjhealth & 0.73 & 0.44 & 0.73 & 0.45 & 0.74 & 0.44 \\
\hline Healthconditions & -0.00 & 0.95 & -0.04 & 0.91 & 0.11 & 0.97 \\
\hline Work & 0.44 & 0.50 & 0.40 & 0.49 & 0.52 & 0.50 \\
\hline Education & 0.64 & 0.66 & 0.67 & 0.66 & 0.57 & 0.64 \\
\hline Pension & 0.10 & 0.29 & 0.08 & 0.28 & 0.10 & 0.30 \\
\hline Wealth & 5.78 & 2.69 & 6.10 & 2.59 & 5.03 & 2.76 \\
\hline House & 0.93 & 0.26 & 0.94 & 0.24 & 0.90 & 0.30 \\
\hline Javanese & 0.49 & 0.50 & 0.47 & 0.50 & 0.54 & 0.50 \\
\hline Muslim & 0.87 & 0.34 & 0.88 & 0.33 & 0.84 & 0.37 \\
\hline Community & 0.86 & 1.15 & 0.82 & 1.12 & 0.95 & 1.20 \\
\hline Java & 0.63 & 0.48 & 0.63 & 0.48 & 0.62 & 0.49 \\
\hline Rural & 0.62 & 0.49 & 0.58 & 0.49 & 0.70 & 0.46 \\
\hline Inherit_house & 0.46 & 0.50 & 0.45 & 0.50 & 0.48 & 0.50 \\
\hline Inherit_care & 0.32 & 0.47 & 0.29 & 0.46 & 0.38 & 0.49 \\
\hline Inherit_gender & 0.70 & 0.46 & 0.70 & 0.46 & 0.69 & 0.46 \\
\hline Inherit_order & 0.11 & 0.31 & 0.13 & 0.34 & 0.10 & 0.30 \\
\hline Inherit_childl & 0.37 & 0.48 & 0.38 & 0.49 & 0.34 & 0.47 \\
\hline Inherit_child 2 & 0.26 & 0.44 & 0.25 & 0.43 & 0.26 & 0.44 \\
\hline Inherit_child3 & 0.49 & 0.50 & 0.48 & 0.50 & 0.49 & 0.50 \\
\hline Parenthouse & 0.76 & 0.42 & 0.77 & 0.42 & 0.75 & 0.43 \\
\hline Parentchoose & 0.42 & 0.49 & 0.43 & 0.49 & 0.41 & 0.49 \\
\hline Nmchildren & 4.41 & 2.38 & 4.65 & 2.46 & 3.88 & 2.10 \\
\hline
\end{tabular}

Note: * statistics computed based on those with a spouse. 
Table 5. Linear regressions of 7-year survival

\begin{tabular}{|c|c|c|c|c|c|c|}
\hline & \multicolumn{2}{|c|}{ Average difference [1] } & \multicolumn{2}{|c|}{ LPM [2] } & \multicolumn{2}{|c|}{ IV-LPM [3] } \\
\hline & Coeff. & t-value & Coeff. & t-value & Coeff. & t-value \\
\hline Coresidence & -0.053 & -2.24 & -0.036 & -1.54 & -0.085 & -0.57 \\
\hline Age & & & -0.006 & -3.38 & -0.006 & -3.40 \\
\hline Female & & & 0.192 & 6.73 & 0.190 & 6.39 \\
\hline Wspouse & & & 0.056 & 0.56 & 0.058 & 0.60 \\
\hline Spouseage & & & 0.000 & -0.14 & 0.000 & -0.27 \\
\hline Childage & & & -0.003 & -2.01 & -0.004 & -1.46 \\
\hline Nmsib & & & 0.005 & 0.90 & 0.005 & 0.91 \\
\hline Subjhealth & & & 0.066 & 2.45 & 0.067 & 2.47 \\
\hline Healthconditions & & & -0.103 & -7.46 & -0.103 & -7.42 \\
\hline Work & & & 0.043 & 1.80 & 0.038 & 1.31 \\
\hline Education & & & -0.019 & -1.00 & -0.018 & -0.91 \\
\hline Pension & & & 0.062 & 1.61 & 0.057 & 1.39 \\
\hline Wealth & & & -0.003 & -0.59 & -0.001 & -0.20 \\
\hline House & & & 0.047 & 1.10 & 0.052 & 1.15 \\
\hline Javanese & & & 0.016 & 0.64 & 0.014 & 0.54 \\
\hline Muslim & & & -0.083 & -2.75 & -0.080 & -2.53 \\
\hline Community & & & 0.033 & 3.19 & 0.032 & 2.90 \\
\hline Java & & & -0.039 & -1.52 & -0.038 & -1.47 \\
\hline Rural & & & 0.032 & 1.34 & 0.028 & 1.11 \\
\hline Constant & & & 1.029 & 6.91 & 1.079 & 5.00 \\
\hline
\end{tabular}

Note: The dependent variable takes a value of one if the respondent is alive in 2007 and zero otherwise. White's robust standard errors are used. LPM stands for linear probability model. The sample size is 1,768 . 
Table 6. Selection equation: coresidence

\begin{tabular}{lrrrlrrr}
\hline & Coeff. & t-value & M.E. & Coeff. & t-value & M.E. \\
\hline Age & -0.006 & -0.701 & -0.001 & Inherit_house & 0.212 & 1.903 & 0.044 \\
Female & -0.347 & -2.453 & -0.073 & Inherit_care & -0.421 & -3.468 & -0.088 \\
Wspouse & 0.148 & 0.279 & 0.031 & Inherit_gender & 0.210 & 1.795 & 0.044 \\
Spouseage & -0.018 & -2.495 & -0.004 & Inherit_order & -0.077 & -0.449 & -0.016 \\
Childage & -0.051 & -6.861 & -0.011 & Inherit_child1 & 0.438 & 2.862 & 0.092 \\
Nmsib & 0.011 & 0.401 & 0.002 & Inherit_child2 & -0.324 & -1.820 & -0.068 \\
Subjhealth & 0.017 & 0.139 & 0.004 & Inherit_child3 & -0.125 & -1.055 & -0.026 \\
Healthcondition & 0.029 & 0.469 & 0.006 & Parenthouse & 0.138 & 1.056 & 0.029 \\
Work & -0.485 & -4.382 & -0.102 & Parentchoose & 0.119 & 1.128 & 0.025 \\
Education & 0.071 & 0.779 & 0.015 & Nmchildren & -0.050 & -0.658 & -0.010 \\
Pension & -0.557 & -2.953 & -0.117 & Nmchildrensq & 0.014 & 2.007 & 0.003 \\
Wealth & 0.121 & 5.922 & 0.025 & Constant & 2.355 & 3.337 & \\
House & 0.446 & 2.338 & 0.093 & & & & \\
Javanese & -0.136 & -1.078 & -0.029 & & & & \\
Muslim & 0.258 & 1.725 & 0.054 & & & & \\
Community & -0.118 & -2.364 & -0.025 & & & & \\
Java & 0.181 & 1.392 & 0.038 & & & & \\
Rural & -0.398 & -3.439 & -0.083 & & & & \\
\hline
\end{tabular}

Note: M.E. denotes marginal effects defined as the analytical derivative averaged over the entire sample. The sample size is 1,768 . 
Table 7. Outcome equations: health outcomes after 7 years

\begin{tabular}{lrrrrrr}
\hline & \multicolumn{3}{c}{ Not in coresidence } & \multicolumn{3}{c}{ In coresidence } \\
& Coeff. & t-value & M.E. & Coeff. & t-value & M.E. \\
\hline Age & -0.011 & -1.154 & -0.002 & -0.018 & -2.486 & -0.005 \\
Female & 0.533 & 2.969 & 0.105 & 0.594 & 4.209 & 0.156 \\
Wspouse & -0.042 & -0.056 & -0.008 & 0.648 & 1.807 & 0.170 \\
Spouseage & -0.003 & -0.280 & -0.001 & -0.006 & -1.256 & -0.002 \\
Childage & -0.008 & -0.709 & -0.002 & -0.008 & -1.234 & -0.002 \\
Nmsib & 0.055 & 1.846 & 0.011 & -0.003 & -0.134 & -0.001 \\
Subjhealth & 0.277 & 1.800 & 0.055 & 0.319 & 3.253 & 0.084 \\
HealthConditions & -0.444 & -4.506 & -0.088 & -0.314 & -5.007 & -0.083 \\
Work & 0.060 & 0.437 & 0.012 & 0.196 & 1.825 & 0.052 \\
Education & -0.131 & -1.223 & -0.026 & -0.021 & -0.318 & -0.006 \\
Pension & 0.377 & 1.648 & 0.074 & 0.218 & 1.475 & 0.057 \\
Wealth & 0.039 & 1.236 & 0.008 & -0.013 & -0.685 & -0.003 \\
House & 0.116 & 0.524 & 0.023 & 0.225 & 1.392 & 0.059 \\
Javanese & 0.161 & 1.090 & 0.032 & 0.177 & 1.869 & 0.046 \\
Muslim & -0.238 & -1.291 & -0.047 & -0.071 & -0.543 & -0.019 \\
Community & -0.022 & -0.414 & -0.004 & 0.131 & 2.743 & 0.034 \\
Java & 0.067 & 0.433 & 0.013 & -0.115 & -1.183 & -0.030 \\
Rural & 0.112 & 0.757 & 0.022 & 0.120 & 1.380 & 0.032 \\
Constant & 1.429 & 1.303 & & 1.086 & 1.948 & \\
Factor $(\hat{\theta})$ & 0.575 & 1.389 & & -0.507 & -1.237 & \\
\hline Cut-off parameters & & & & & & \\
$\hat{\tau}_{1}$ & 0.104 & 5.301 & & & & \\
$\hat{\tau}_{2}$ & 0.811 & 7.154 & & & & \\
$\hat{\tau}_{3}$ & 3.038 & 7.693 & & & \\
\hline Not & & & & & & \\
\hline
\end{tabular}

Note: M.E. denotes marginal effects defined as the analytical derivative averaged over the entire sample. The sample size is 1,768 . 
Table 8: Mean and distributional treatment parameters on 7-year survival

\begin{tabular}{lr}
\hline$A T E$ (average treatment effect): & -0.100 \\
Standard error: & 0.078 \\
p-value: & 0.197 \\
\hline \hline $\operatorname{Pr}(\Delta=1)$ (probability of survival due to coresidence): & 0.125 \\
$\operatorname{Pr}(\Delta=0)$ (probability of no effect on survival): & 0.650 \\
$\operatorname{Pr}(\Delta=-1)$ (probability of death due to coresidence): & 0.225 \\
\hline \hline ATT (average treatment effect on the treated): & -0.189 \\
Standard error: & 0.095 \\
p-value: & 0.046 \\
ATUT (average treatment effect on the untreated): & 0.123 \\
Standard error: & 0.119 \\
p-value: & 0.300 \\
\hline
\end{tabular}

Note: Treatment parameters are computed based on the point estimates of the full model. 
Table 9: Correlations between observables, unobservables, and treatment effect

\begin{tabular}{lrllll}
\hline $\operatorname{Corr}\left(X \beta_{0}, X \beta_{1}\right)=$ & 0.815 & $\operatorname{Corr}\left(Z \beta_{D}, X \beta_{0}\right)=$ & 0.094 & $\operatorname{Corr}\left(Z \beta_{D}, X \beta_{1}\right)=$ & -0.150 \\
$\operatorname{Corr}\left(U_{0}, U_{1}\right)=$ & -0.225 & $\operatorname{Corr}\left(U_{D}, U_{0}\right)=$ & 0.353 & $\operatorname{Corr}\left(U_{D}, U_{1}\right)=$ & -0.320 \\
$\operatorname{Corr}\left(Y_{0}^{*}, Y_{1}^{*}\right)=$ & 0.813 & $\operatorname{Corr}\left(D^{*}, Y_{0}^{*}\right)=$ & 0.094 & $\operatorname{Corr}\left(D^{*}, Y_{1}^{*}\right)=$ & -0.150 \\
\hline $\operatorname{Corr}\left(Z \beta_{D}, X \beta_{1}-X \beta_{0}\right)=$ & -0.396 & & & \\
$\operatorname{Corr}\left(U_{D}, U_{1}-U_{0}\right)=$ & -0.430 & & & \\
$\operatorname{Corr}\left(D^{*}, Y_{1}^{*}-Y_{0}^{*}\right)=$ & -0.396 & & & \\
\hline
\end{tabular}


Table 10. Marginal effects (M.E.) of covariates on average treatment effect (ATE)

\begin{tabular}{lrrlrr}
\hline & M.E. on ATE & $\mathrm{t}$-value & M.E. on ATE & $\mathrm{t}$-value \\
\hline Age & -0.002 & -0.876 & Pension & -0.017 & -0.248 \\
Female & 0.051 & 0.885 & Wealth & -0.011 & -1.486 \\
Wspouse & 0.179 & 0.985 & House & 0.036 & 0.556 \\
Spouseage & -0.001 & -0.423 & Javanese & 0.015 & 0.359 \\
Childage & 0.000 & -0.135 & Muslim & 0.028 & 0.501 \\
Nmsib & -0.012 & -1.348 & Community & 0.039 & 2.556 \\
Subjhealth & 0.029 & 0.716 & Java & -0.043 & -1.080 \\
Healthconditions & 0.005 & 0.147 & Rural & 0.009 & 0.233 \\
Work & 0.040 & 0.978 & & & \\
Education & 0.020 & 0.679 & & & \\
\hline
\end{tabular}


Table 11: Health transition matrix and conditional ATEs

\begin{tabular}{lcc}
\hline & \multicolumn{2}{c}{ Baseline health status (2000) } \\
\cline { 2 - 3 } Health outcome (2007) & $\begin{array}{c}\text { Healthy } \\
\text { (Very /somewhat healthy) }\end{array}$ & $\begin{array}{c}\text { Unhealthy } \\
\text { (Very /somewhat unhealthy) }\end{array}$ \\
\hline Very healthy & 2.79 & 1.05 \\
Transition rate (\%) & -5.17 & -2.22 \\
ATE (ppts) & & \\
\hline Somewhat healthy & 47.76 & 24.79 \\
Transition rate (\%) & -8.92 & -11.70 \\
ATE (ppts) & & \\
Somewhat unhealthy & 20.12 & 26.26 \\
Transition rate (\%) & +4.21 & +1.05 \\
ATE (ppts) & & 3.57 \\
\hline Unhealthy & 2.71 & +0.05 \\
Transition rate (\%) & +0.07 & 44.33 \\
$A T E$ (ppts) & & +12.40 \\
\hline Dead & 26.63 & \\
Transition rate $(\%)$ & +9.14 & \\
$A T E$ (ppts) & & \\
\hline
\end{tabular}




\begin{tabular}{|c|c|c|}
\hline & $A T E$ & t-stat \\
\hline (1) Unconditional mean differences ${ }^{\mathrm{a}, \mathrm{e}}$ & -0.053 & -2.233 \\
\hline (2) Linear probability model without selection on unobservables ${ }^{b, c, e}$ & -0.036 & -1.542 \\
\hline (3) Linear IV b,d,e & -0.085 & -0.569 \\
\hline (4) Probit model without selection on unobservables ${ }^{\mathrm{c}, \mathrm{e}, \mathrm{f}}$ & -0.036 & -1.496 \\
\hline (5) Probit model IV d,e,f & -0.104 & -0.450 \\
\hline (6) Probit model, heterogeneous effect, without selection on unobservables ${ }^{c, e, f}$ & -0.025 & -0.258 \\
\hline (7) Probit model, heterogeneous effect, selection on unobservables ${ }^{\mathrm{d}, \mathrm{e}, \mathrm{f}}$ & \multicolumn{2}{|c|}{ Convergence unstable } \\
\hline (8) 3 categorical, constant effect, without selection on unobservables ${ }^{c, f, g}$ & -0.044 & -2.172 \\
\hline (9) 3 categorical, heterogeneous effect, without selection on unobservables ${ }^{\text {c,f,h }}$ & -0.038 & -0.455 \\
\hline (10) 3 categorical, heterogeneous effect, selection on unobservables $\mathrm{d}, \mathrm{f}$ & -0.110 & -1.449 \\
\hline (11) 5 categorical, constant effect, without selection on unobservables ${ }^{c, f, g}$ & -0.048 & -2.492 \\
\hline \multirow{2}{*}{$\begin{array}{l}\text { (12) } 5 \text { categorical, heterogeneous effect, without selection on unobservables }{ }^{\mathrm{c}, \mathrm{f}, \mathrm{h}} \\
\text { (13) } 5 \text { categorical, heterogeneous effect, selection on unobservables (our } \\
\text { preferred model) } \mathrm{d,f}\end{array}$} & -0.039 & -0.483 \\
\hline & -0.100 & -1.293 \\
\hline
\end{tabular}

Note: 3 categories consist of \{Healthy, Unhealthy, Dead\} and 5 categories \{Very health, Somewhat health, Somewhat unhealthy, Unhealthy, Dead

${ }^{\mathrm{a}} \hat{\mathrm{E}}\left(\mathrm{Y}_{1} \mid \mathrm{D}=1\right)-\hat{\mathrm{E}}\left(\mathrm{Y}_{0} \mid \mathrm{D}=0\right)$.

${ }^{\mathrm{b}}$ Linear probability model of Survive on Coresidence and other covariates with a common treatment assumption, $\mathrm{Y}=\mathrm{X} \beta+\gamma \mathrm{D}+\mathrm{U}$.

${ }^{\mathrm{c}}$ Coresidence is assumed to be exogenous.

${ }^{\mathrm{d}}$ Coresidence is assumed to be endogenous and estimation is with the instruments listed in Table 3.

e The dependent variable $\mathrm{Y}=1$ if a parent survives and 0 otherwise.

${ }^{\mathrm{f}}$ Maximum likelihood estimation with normally distributed unobservables.

${ }^{\mathrm{g}}$ A standard ordered probit model.

${ }^{\mathrm{h}}$ No selection on unobservables imposes $\alpha_{0}=\alpha_{1}=0$. 
Figure 1: Baseline health, health outcomes, and coresidence status

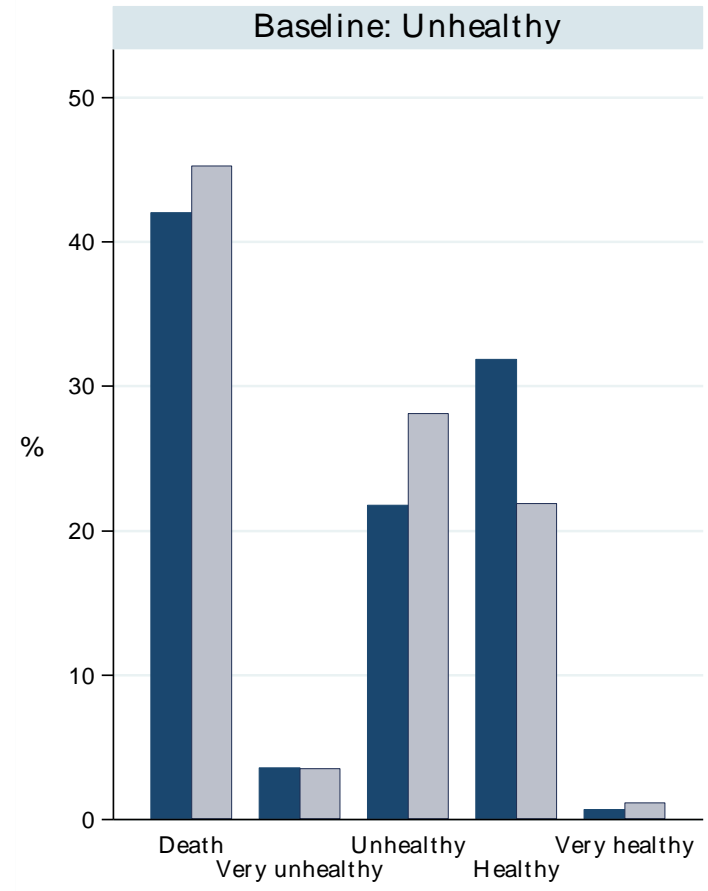

Non coresidence

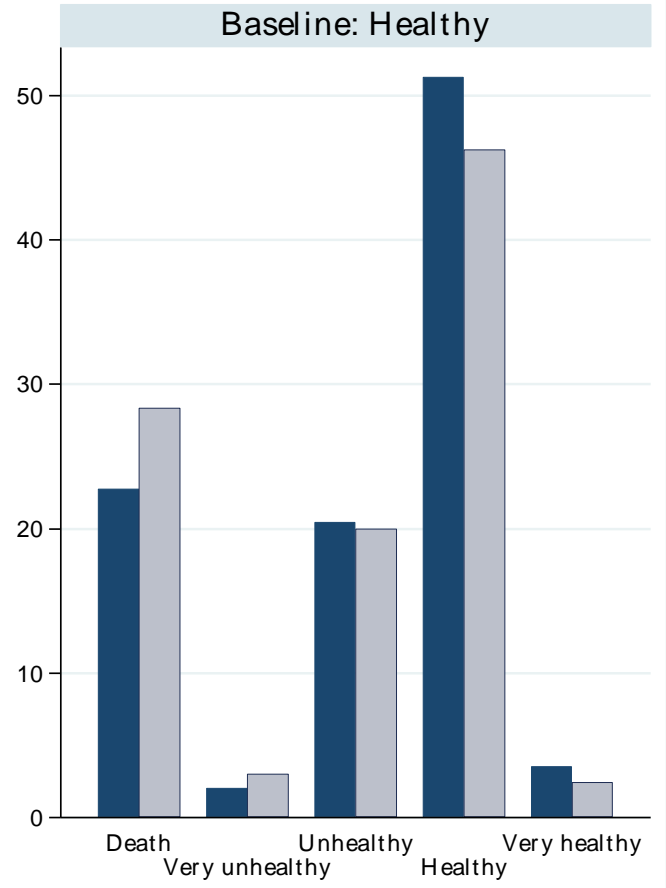

Coresidence

Note: The vertical axis indicates the sample proportion for each health outcome. For example, 46 percent of coresiding parents who were unhealthy in the base year died within the next seven years. 
Figure 2. Estimated Marginal Treatment Effect (MTE)

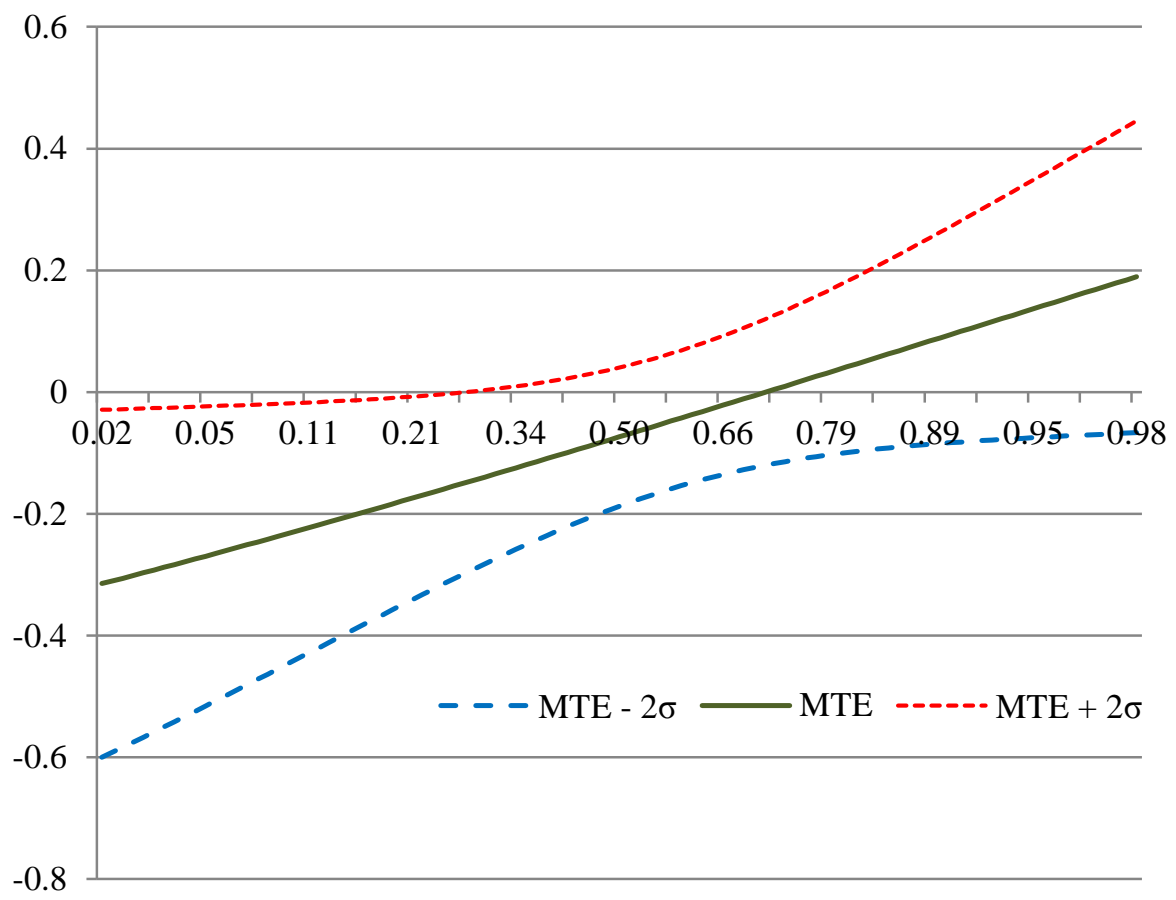

Note: The horizontal axis represents the value of $U_{D}$, labelled by its cumulative probability. The vertical axis measures the size of the MTE. 